\title{
Strategies for academic and research excellence for a young university: perspectives from Singapore
}

\author{
Chin-Heng Lim*, Freddy Boey
}

Administration Building, Nanyang Technological University, 50 Nanyang Avenue, Singapore 639798

\begin{abstract}
As countries worldwide have become increasingly interconnected due to globalisation, universities have likewise undergone significant changes. To achieve and maintain academic and research excellence in today's fast-paced knowledge economy, it is critical for international universities to transcend traditional education. With the blurring of boundaries and rise of Asia, universities worldwide have increased collaborative efforts. Several Asian universities have acquired top academic rankings and achieved international recognition in parity with many western iconic counterparts. These rankings have galvanised the world of higher education, resulting in a virtuous circle impact on universities' drive for academic and research excellence. Since the emergence of global rankings, universities have been compared on a national and international basis and this has affected the way they operate. The rankings - used as a tool to maintain and build institutional position and reputation - have also resulted in an increasing trend of policy makers utilising the ranking results to make decisions on resource allocation or structure of higher education systems. The Singapore universities, which are crucial for elevating Singapore's society towards the future knowledge economy, have transformed rapidly from teaching institutions into top international research-intensive universities. This article examines how Nanyang Technological University (NTU) strategises its progress and establishes platforms for the creation of greater scientific knowledge and research innovation, which impact on higher education rankings and vice versa. Some of the issues covered include institutional management structure, talent retention/attraction, research competitiveness, and international and industry collaborations.
\end{abstract}

KEY WORDS: Higher education · University rankings $\cdot$ Research-intensive $\cdot$ Institutional management $\cdot$ International collaborations $\cdot$ Talent management

\section{INTRODUCTION}

Rankings are ever-present in today's world and they are used everywhere, including for airlines, hospitals and credit ratings (Rauhvargers 2011, 2013). The emergence of university rankings/benchmarking has led to a revolution in the way universities or institutions of higher education operate (Hazelkorn 2007, IHEP 2009). The concept of rankings has gained great importance as a tool for all stakeholders of the higher education landscape. The rankings, which can be used as a tool to maintain and build institutional position and reputation, have also re- sulted in an increasing trend of policy makers utilising the ranking results to make decisions on resource allocation or structure of the higher education systems. The rankings are used either as performance indicators or as tools for choosing places of study (Hazelkorn 2008, Marginson 2008). Though concerns about ranking methodologies have been raised, such as rankings being retrospective and not taking into consideration the establishment period of universities (Saisana \& D'Hombres 2008, Loobuyck 2009, Badat 2010), rankings are here to stay and cannot be ignored. If communicated and used correctly, rankings provide useful information and showcase acade- 
mia in the global society. The challenge is to ensure they are not misused or over-interpreted.

Asia's countries have made a global impact in the higher education landscape and the various rankings systems. No longer is the academic scene made up only of heavyweights from Europe and the United States of America. In recent years, several Asian universities have acquired top rankings in parity with many western iconic institutions. Nanyang Technological University (NTU) has done relatively well in world university rankings and has consistently been ranked among the top 100 universities in the world - the elite top $1 \%$. The National University of Singapore has also been ranked consistently within the elite top $1 \%$, which makes Singapore one of the few small countries to have achieved the feat of having 2 universities ranked in the top 100 (New Straits Times 2013, Teng 2013).

NTU was founded in 1955 as Nanyang University, merged with the University of Singapore in 1980, reestablished as Nanyang Technological Institute in 1981, and inaugurated as Nanyang Technological University (NTU) in 1991 (NTU's corporate information, www.ntu.edu.sg/AboutNTU/CorporateInfo/ Pages/Ourhistory.aspx). Since its establishment in 1991, NTU has undergone fundamental changes and made dramatic progress in education and research. A locally oriented Chinese university in the 1950s, NTU is now a large international English-language university well-recognised by its peers from around the world. NTU is a cosmopolitan campus with a large community of foreign faculty and students, playing host to Nobel Laureates, visiting professors and overseas exchange students. NTU students participate actively in overseas programmes. We have a rich international network and played a leading role in the formation of the Global Alliance of Technological Universities (GlobalTech Alliance). GlobalTech groups the California Institute of Technology and Georgia Institute of Technology in the USA, Imperial College London and ETH Zurich in Europe, and the Indian Institute of Technology Bombay, Shanghai Jiao Tong University and NTU in Asia. Given NTU's heritage, we have especially strong links with China, through our alumni and established programmes such as the 'Mayors' Class' and the Executive MBA.

NTU has come a long way since its founding. As Nanyang Technological Institute in the 1980s, the university offered only engineering programmes.
While engineering remains our core, we now have a diversity of strengths in business, science, humanities, education, international studies, arts and social sciences, and most recently, the establishment of the Lee Kong Chian School of Medicine - a collaboration with Imperial College London. Even more recent is the steep rise in research intensity, a remarkable achievement given the previous teaching focus of the university. NTU is the 8th most-cited institution in engineering for 1999 to 2009 in Thomson-Reutersindexed Engineering journals, based on the top 1\% ranked by total citation count, with 5192 papers cited a total of 28516 times, as presented by Essential Science Indicators (Science Watch 2010). We have built up a wide research base with acknowledged strengths in specific domains over a short period of time. The increase in competitive research funding testifies to our steep ascent in research. NTU's rapid growth between 2005 and 2012 in terms of student enrolment, top student intake, competitive research grants, number of faculty and research staff, and citations per publication is shown in Table 1.

As a large research-intensive university, NTU has a critical role to play in the academic ecosystem and in powering Singapore's continued growth. NTU is a multi-disciplinary university with one of the largest and highly rated engineering colleges in the world and a well-regarded business school. NTU has the critical mass to provide the breadth and depth of research and knowledge across a wide spectrum of engineering disciplines. The multi-disciplinary breadth with engineering at the core places NTU in a unique position to exploit the strategic interfaces between these academic fields with engineering as the 'vector discipline'. The NTU structure is illustrated in Fig. 1.

Within a few decades, NTU has risen to be consistently ranked among the top 100 universities in the world - the elite top $1 \%$. In the Quacquarelli Sy- 


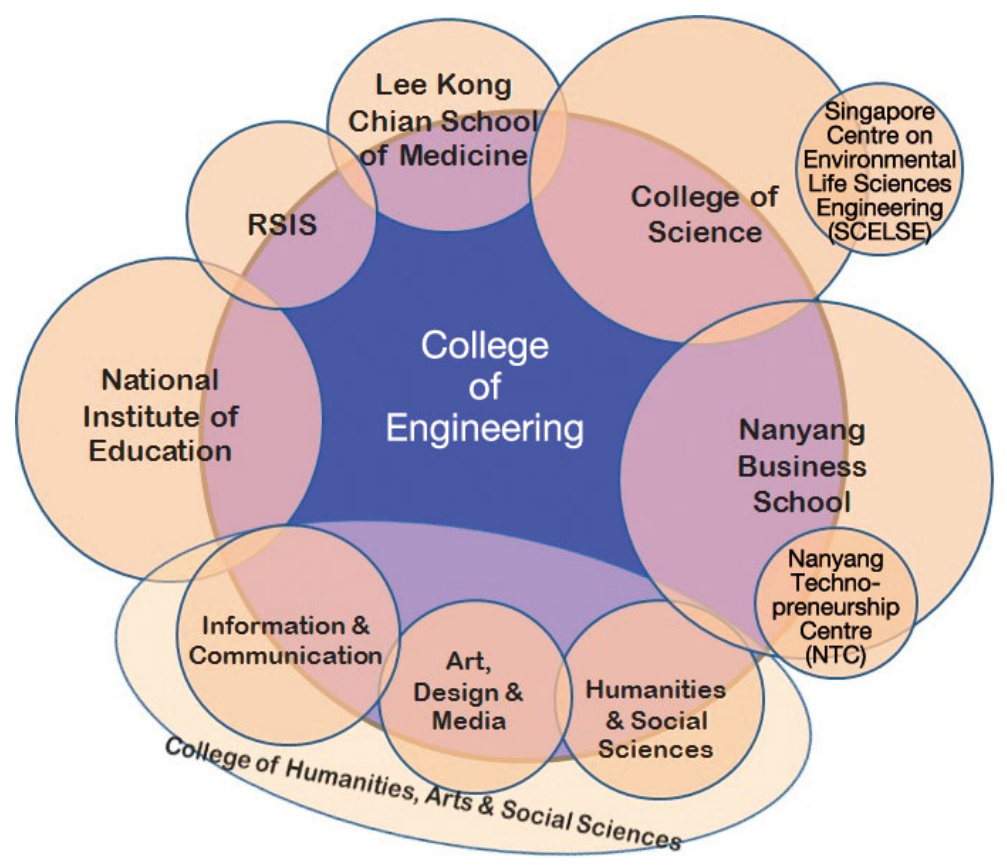

Fig. 1. The College structure of the Nanyang Technical University. RSIS: S. Rajaratnam School of International Studies (source: NTU)

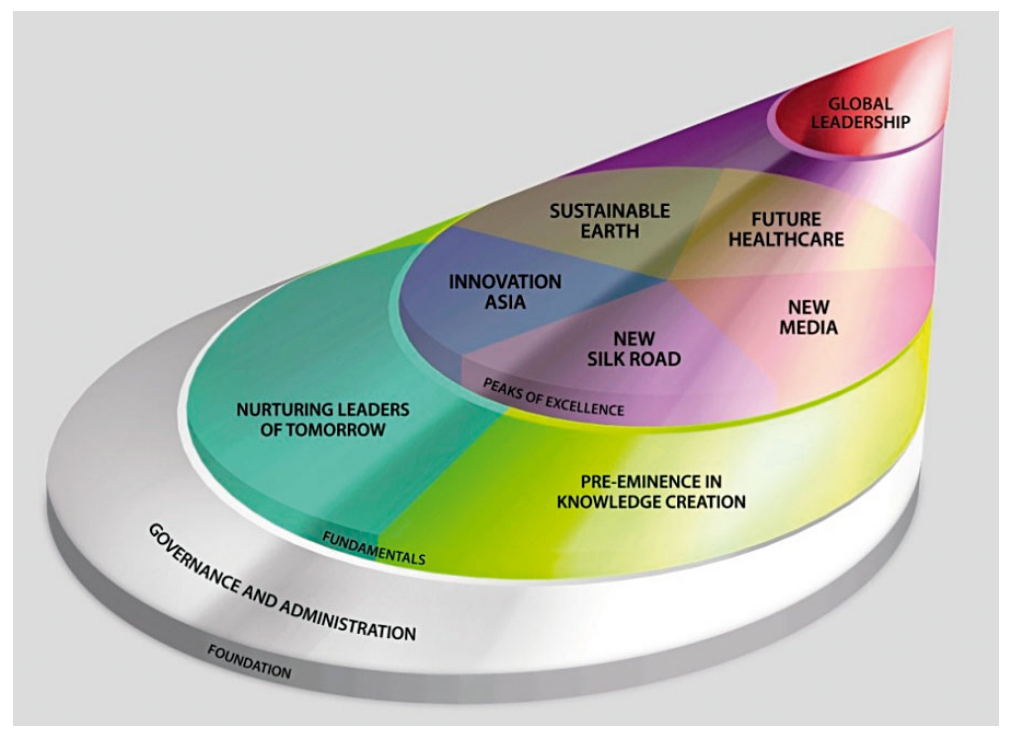

Fig. 2. The Nanyang Technical University's 2015 strategy (source: NTU)

NTU's reputation was also enhanced by being ranked 4 th in the world for young universities under $50 \mathrm{yr}$ old. The new league table of the world's young universities - the QS top 50 under 50-has NTU as the only Singapore university to be ranked within the top 50. In another similar ranking by Times Higher Education, NTU was ranked 16th among the top 100 of the world's major young universities.

As a young university, being in the world's top 50 is a remarkable milestone and reaffirms our global standing in education and research.

\section{STRATEGIES FOR ACADEMIC AND RESEARCH EXCELLENCE - NTU AS A CASE STUDY}

\section{Strong government commitment}

NTU's transformation and progress in recent years has come at a time of momentous change in Singapore's higher education sector. Three major developments are particularly important. These are the boost in public sector investment in research and development, the expansion of the university cohort participation rate, and the grant of autonomy to all publicly funded universities. NTU capitalised on these developments to rapidly build up our research capabilities and expand capacity and educational offerings. With our status as an autonomous university, we have also moved to chart our own destiny. Singapore's move towards a more knowledge-based society and an innovation-driven economy opens up many opportunities for NTU. The

monds (QS) World University Rankings 2012/2013, NTU was ranked $47 \mathrm{th}$. This is the first time ever that NTU has been ranked among the world's top 50 universities and this was achieved in a spectacular fashion with NTU jumping 11 places in 2012 and 16 places in 2011. The quantum leap of 27 places over 2 yr makes NTU the fastest-rising university in the global top 50. NTU also made a leap in the Times Higher Education World University Rankings 2012 by making a noticeable 83-place jump to be ranked 86th among the top 100. country's reputation as an education and research hub with a host of top foreign universities and foreign companies provides a rich environment for growth and collaboration.

\section{NTU 2015 strategic plan}

In November 2010, NTU unveiled a strategic plan to guide its development over the next 5 yr (Fig. 2). Our vision and mission are to be 'a great global uni- 
versity founded on science and technology, nurturing creative and entrepreneurial leaders through a broad education in diverse disciplines'.

In aiming to be a broadly based university of science and technology, which also includes top schools in other disciplines, we want to be especially renowned throughout the world for 5 interdisciplinary Peaks of Excellence: Sustainable Earth, Future Healthcare, New Media, New Silk Road and Innovation Asia. Indeed, we are well-positioned in these 5 areas and already among the world leaders in Sustainable Earth in terms of securing external research funding. To date, NTU has secured more than 1 billion Singapore dollars in external research funding. Broad and inclusive, the Peaks of Excellence are drawn from the strengths of the university and the past and current work of the colleges, schools and faculty. They will be built upon the strong fundamentals of Education and Research. As a publicly funded research-intensive university, NTU has a dual role - to create and to disseminate knowledge. This is in line with the 'Humboldtian' philosophy that teaching and research are mutually reinforcing (Anderson 2004). NTU will continue to elevate its Education and Research fundamentals. It is on this upward shift of the underlying landscape that Peaks of Excellence will emerge, some with deliberate nurturing. Education and Research will in turn have to be supported and enabled by a strong Administration and Governance.

\section{Governance and management}

In the last $5 \mathrm{yr}$, there has been a deep and extensive restructuring of our governance and management structures. An important development arising from NTU's corporatisation in 2006 was the appointment of a Board of Trustees, which took on greater ownership and more involvement in the development of the university. The Trustees became much more involved in the development of NTU. NTU also reformed its top management and academic structure to sharpen its academic focus and streamline decision-making. The Provost appointment was created in 2007 as the chief academic officer. A College structure was formed with 12 Schools grouped into 4 Colleges (Engineering, Science, Business and Humanities, Arts and Social Sciences), each headed by a Dean with direct accountability to the Provost. The College structure has facilitated greater collaboration and synergy across NTU.
The President-Provost and College structure is complemented by several management committees, including the University Cabinet, the President's Coordinating Group, the Provosts-Deans Group and the Administrative Committee. With these changes, the academic structure and leadership have been strengthened considerably, with international talent brought in to fill a number of the senior appointments. The academic structure is bolstered by the Academic Council and the Senate, which acts on behalf of the Academic Council. The Academic Council gives the faculty body an official platform to articulate their views, engage university management and contribute to the development of NTU.

Resource allocation delivers strategic objectives and shapes desired behaviours. Our budget process was reformed with the introduction of performancebased teaching and research drivers, a central strategic fund to support key teaching and research initiatives, and an inter-school contribution model to motivate inter-disciplinary teaching amongst colleges and schools. Led by the Provost, the budget process is interactive, impactful and transparent. There are extensive discussions with colleges, schools and administration throughout the budget exercise.

In 2008, NTU also started an Administrative Excellence initiative with the view of fostering change through selected leverage projects aimed at improving service excellence for students and faculty. A business process re-engineering study is now ongoing, to be followed by systems design and reorganisation.

\section{Undergraduate education}

As one of the 2 large public universities in Singapore, education remains a top priority of NTU. In August 2007, as part of our continual efforts to update and strengthen education, NTU formed a Blue Ribbon Commission (BRC) to conduct a bottom-up, fundamental review of undergraduate education. The resulting BRC Report, which also identifies the desired attributes of university graduates, serves as the blueprint to guide the development of an holistic undergraduate education. These attributes are (1) ethical reasoning, integrity and moral character; (2) leadership, teamwork, mutual respect and communication skills; (3) professionalism, public service, social engagement and global citizenship; (4) self-discipline, disciplinary depth and lifelong learning; and (5) creativity, innovation and interdisciplinary synthesis. 
A BRC Implementation Committee has translated the recommendations into concrete plans and initiatives. A key change is in the fundamental structure of the curriculum, with the main focus on the 3 'Is' in learning:

(1) Interactive learning: Students know how to acquire knowledge easily, but interactive skills are the edge they need;

(2) Inspirational learning: Learning by being inspired by challenges in research themes and top researchers on campus;

(3) Institutional learning: A place remains for disciplined and structured learning on campus; sense of belonging to an eminent institution.

While maintaining academic rigour and depth, prescribed core requirements will be reduced and more breadth and new multi- and inter-disciplinary courses will be introduced. This is complemented by initiatives to foster excellence in teaching and effectiveness in learning. NTU is in the process of modernising the teaching and learning infrastructure and, in particular, there will be even greater leverage and use of information technology. In March 2013, the university launched the NTU Education - a blueprint to develop graduates for the 21st century workplace. NTU education is dedicated to creating knowledge to meet the global challenges of the 21st century and nurturing innovative and socially responsible leaders to shape the future of Singapore, Asia and beyond with optimism and confidence.

As the quality of undergraduate education is raised to benefit the entire student body, efforts are also being made to attract and nurture high achievers. In recent years, NTU launched the premier scholarship programmes - University Scholars Programme and Renaissance Engineering Programme - to attract top

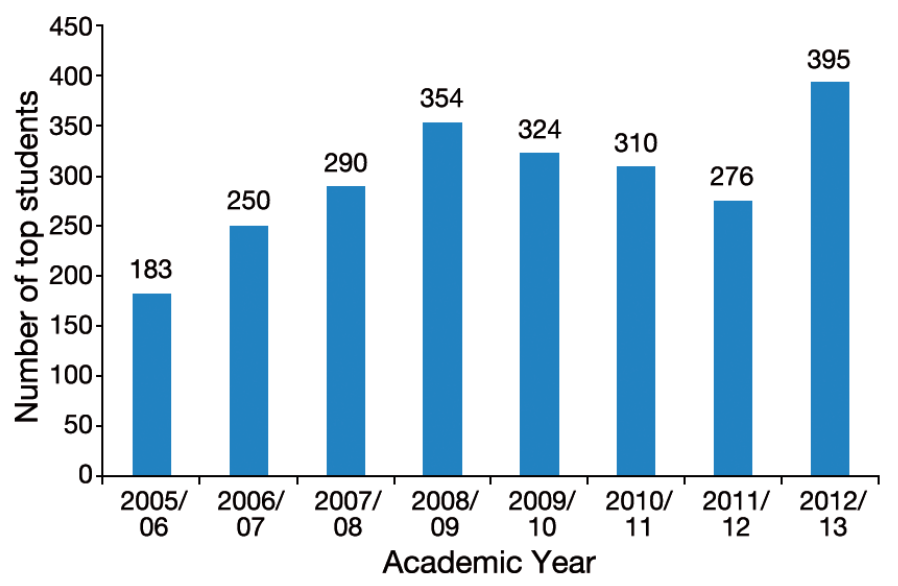

Fig. 3. Top student intake; Nanyang Technical University, 2005 to 2013 (source: NTU's official statistics) students, which are defined as the top $15 \%$ of students sitting the Singapore-Cambridge General Certificate of Education (GCE) Advanced-Level (ALevel) examination in each annual cohort. Despite a historical disadvantage in not providing programmes traditionally preferred by top students such as law, medicine and dentistry, we have seen good success in attracting top students at the last admission of new students. The number of top students choosing NTU more than doubled from academic year 2005 to 2012, increasing from 183 to 395 (Fig. 3, see also Table 1).

\section{Graduate education}

Graduate education constitutes a strategic component of NTU in its vision to become a researchintensive university. NTU has directed its efforts to enhance graduate education in 3 key aspects: (1) partnering renowned overseas universities to provide a global perspective for graduate programmes and strengthen global reputation; (2) widening the international recruitment network to enlarge the talent pool of graduate students; and (3) undertaking curriculum review to attain peaks of excellence in research.

NTU has taken a big step towards globalising its research programmes by establishing joint $\mathrm{PhD}$ programmes with top universities such as Imperial College London, Technical University of Munich, Karolinska Institutet, Carnegie Mellon University and Technische Universität Darmstadt. Such joint degree programmes help to attract top quality graduate students to NTU's PhD programmes, offering a series of interrelated benefits for students, staff and universities alike. In particular, this helps to combine the universities' strength in attracting outstanding researchers for future collaborative projects.

Inter-disciplinary research has become one of the key strategic thrusts at NTU. An inter-disciplinary graduate school, with a thematic research focus, has been established to bring graduate education into greater alignment with the university's research focus on multi-disciplinary, integrative research. Several thematic areas have been initially identified, namely life sciences and engineering, water and environmental studies, interactive digital media, and energy research. Such an inter-disciplinary school set-up not only supports, reinforces and enhances collaborations, but also attracts significant amounts of research project funds. We envisage that the graduate school will eventually 
cater for $30 \%$ of the university's annual PhD student intake.

NTU's intake of PhD students has also become more internationalised, with quality rising in tandem with an increase in recruitment, which has stretched beyond Asia to include non-traditional sources in North and South America and Europe. NTU has created, or is involved in, various research scholarship schemes to target different student profile groups.

NTU has undertaken a major review of its graduate programmes by research, as it expands graduate recruitment to support its research drive. PhD courses have increased by over $50 \%$ from 191 in academic year 2006 to 296 in 2009. Highly specialised courses with typically low enrolment are decentralised to the schools to manage resource planning of small classes more effectively.

\section{RESEARCH AND COLLABORATIONS}

Up until the early 2000s, NTU's fundamental focus was on teaching with pockets of research groups predominantly in engineering fields. Over the last few years, major initiatives to transform NTU into a research-intensive university have been launched. These include the implementation of a new academic structure, reform of the faculty appointment, promotion and tenure system, infusion of faculty talent, introduction of research quality drivers in the budget process, implementation of strategic research directions, and strengthening of the research-innovation nexus. These changes are in tandem with NTU's renewed emphasis on research $\leftrightarrow$ innovation linkage, especially through partnerships with leading technology-based multinational companies and industry technology leaders.

Fostering inter-disciplinary research is critical to research excellence. Increasingly, new scientific and technological breakthroughs and solutions to global problems reside in inter-disciplinary domains. But good interdisciplinary work rests on disciplinary depth, so the latter will continue to be developed. To build up core research excellence, NTU has prioritised and galvanised our resources towards areas in which we have particular strengths and which are in alignment with the national strategic thrusts. Several interdisciplinary strategic areas - Sustainable Earth, Future Healthcare and New Media - have been identified. Pan-university research institutes have been established to drive these interdisciplinary research directions. In Sustainable Earth, the re-

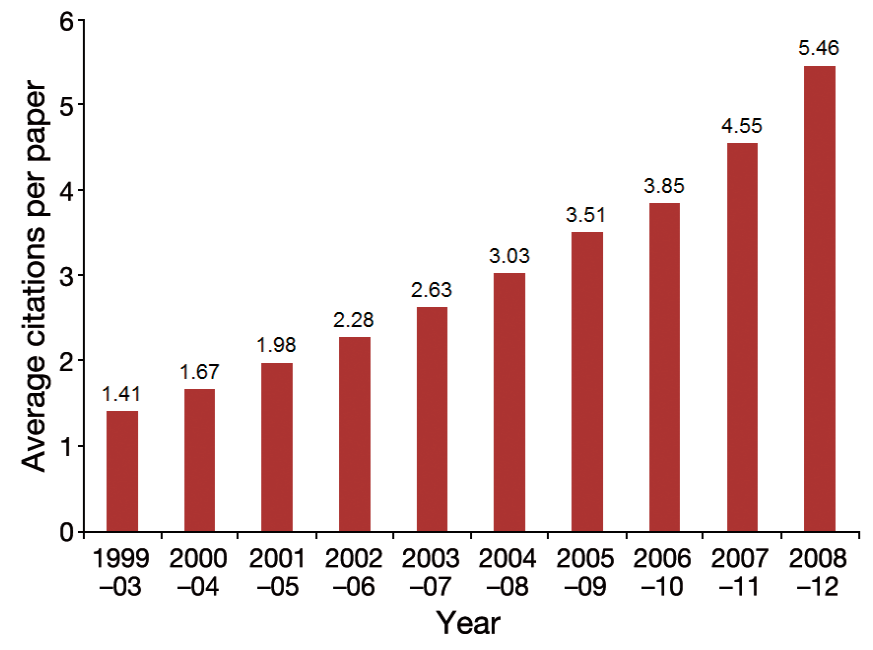

Fig. 4. Average citations per paper (5 yr interval); Nanyang Technical University, 1999 to 2012 (source: Essential Science Indicator, November 2012)

search institutes - Earth Observatory of Singapore (EOS), Singapore Centre on Environmental Life Sciences Engineering (SCELSE), Nanyang Environment and Water Research Institute and Energy Research Institute-have together secured more than 1 billion Singapore dollars of research funding. EOS and SCELSE are funded through the Singapore National Research Foundation's (NRF) Research Centres of Excellence initiative. In Future Healthcare, NTU has successfully consolidated research excellence in biosciences, and with the new medical school in the pipeline, is poised to make significant contributions in bio-engineering at the interface between medicine and engineering. In New Media, through the creation of the Institute for Media Innovation, NTU has developed an interactive platform to bring together the various interactive digital mediarelated research activities within the university.

The successes of our strategies and initiatives are evidenced by research outcomes. Publications and citations have all increased during the last $12 \mathrm{yr}$ (Figs. 4, 5 \& 6, Table 1). NTU is the 8th most-cited institution in engineering for 1999 to 2009 in Thomson-Reuters-indexed Engineering journals, as presented by Essential Science Indicators (Science Watch 2010). In addition, there has been a linear increase in external competitive research grants awarded (Fig. 7).

NTU is involved in an array of collaborative research activities with leading universities around the world, including CREATE (Campus for Research Excellence and Technological Enterprise), an initiative spearheaded by Singapore's NRF (Singapore 


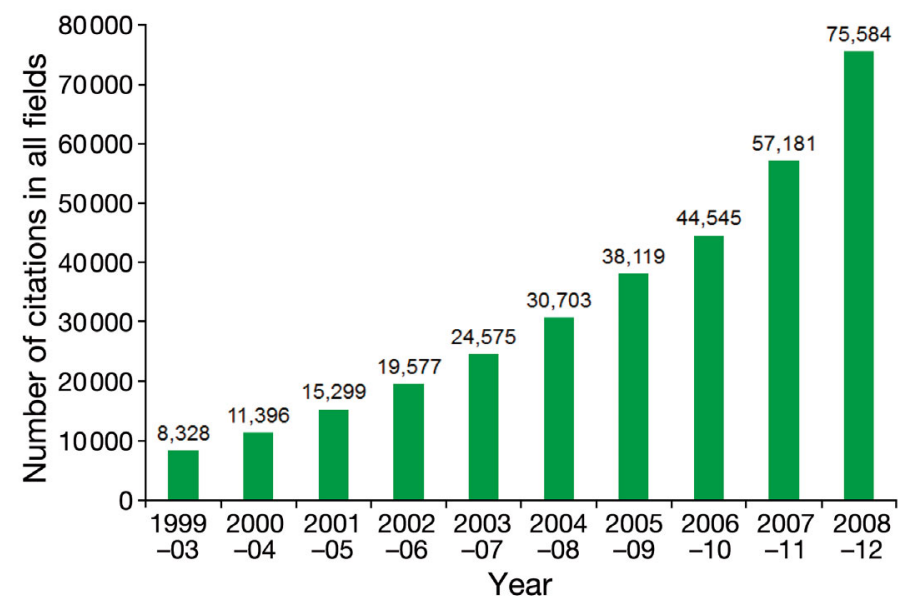

Fig. 5. Number of citations in all fields (5 yr interval); Nanyang Technical University, 1999 to 2012 (source: Essential Science Indicator, November 2012)

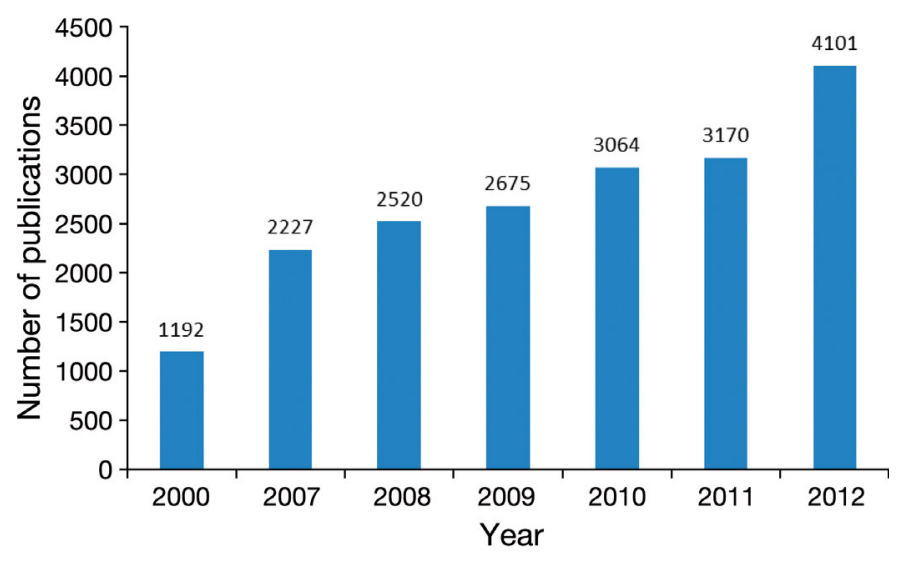

Fig. 6. Number of publications; Nanyang Technical University, 2000 to 2012 (source: NTU)

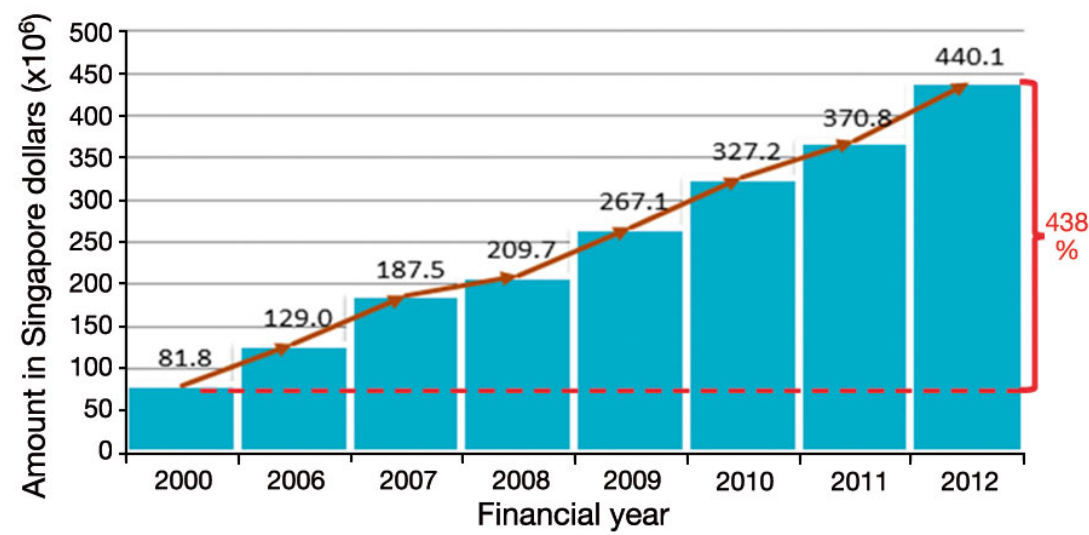

Fig. 7. Annual external research grant awards (by fiscal year); Nanyang Technical University, 2005 to 2012 (source: NTU)
NRF-CREATE Programme: www.nrf.gov.sg/about-nrf/ programmes/create) to attract several leading research universities, including Technical University of Munich, Cambridge University, University of California, Berkeley, Massachusetts Institute of Technology, ETH-Zurich, Technion-Israel Institute of Technology, Hebrew University and Peking University, to establish research teams in Singapore and conduct advanced research in partnership with local institutions.

Beside the CREATE initiative, NTU has forged key partnerships with several leading overseas universities in areas of strategic importance. Examples of these universities are those who have joint $\mathrm{PhD}$ programmes with NTU, as mentioned earlier. Such concerted efforts enable NTU to develop key research foci for research collaborations with strategic overseas research partners in which NTU can take a forefront position.

NTU faculty have also been proactively engaging multinational companies in collaborative initiatives. These industrial collaborations are a key component of a world-class technological university, testament to the relevance of NTU's research expertise to real life problems and to the pressing needs of industry. NTU's world-renowned research partner organisations and companies include Rolls-Royce, Lockheed Martin, IBM, Fraunhofer Gesellschaft, CNRS, Thales, EADS, DLR, Bosch, Siemens, Robert Bosch and Zeiss. The majority of these partnerships are either co-funded or fully funded research projects conducted by our faculty with shared intellectual property arrangements. Such arrangements represent fertile opportunities for industry-academia interactions that will spawn spinoff companies and high-tech start-up companies.

\section{FACULTY APPOINTMENT, PROMOTION AND TENURE}

The essence of a world-class research-intensive university is found within its talent pool: a world-class university is not just about bricks, it is about brains. NTU realises the need to secure the highest-calibre faculty and researchers to generate new ideas, identify and lead research initiatives and put together high-quality research proposals. NTU has successfully attracted many eminent professors (Table 2) to join as full-time faculty in recent years in research areas that place NTU on the world map. 
Table 2. Top recruited scientists at Nanyang Technical University. EPFL: École polytechnique fédérale de Lausanne; IMCB: Institute of Molecular and Cell Biology; A*STAR: Agency for Science, Technology and Research

\begin{tabular}{|c|c|c|}
\hline Name & Research area & Institute of origin \\
\hline Professor James BARBER & Artificial photosynthesis & Imperial College London, UK \\
\hline Professor Michael GRAETZEL & Nanostructured photosystems & EPFL, Switzerland \\
\hline Professor Philip W. INGHAM & $\begin{array}{l}\text { Cardiovascular development and } \\
\text { cellular biology }\end{array}$ & IMCB, A*STAR, Singapore \\
\hline Professor Staffan KJELLEBERG & Bacterial biofilm biology & $\begin{array}{l}\text { University of New South Wales, } \\
\text { Australia }\end{array}$ \\
\hline Professor Bo LIEDBERG & $\begin{array}{l}\text { Self-assembly, surface modification } \\
\text { and surface vibrational spectroscopy }\end{array}$ & Linköping University, Sweden \\
\hline Professor Chris NEWHALL & Earth sciences & US Geological Survey, USA \\
\hline Professor Par NORDLUND & Structural genomics & Karolinska Institutet, Sweden \\
\hline Professor Daniela RHODES & $\begin{array}{l}\text { Structure and function of chromatin } \\
\text { and telomeres }\end{array}$ & $\begin{array}{l}\text { MRC Laboratory of Molecular Biology, } \\
\text { University of Cambridge, UK }\end{array}$ \\
\hline Professor Charles T. SALMON & $\begin{array}{l}\text { Intersection of public communication, } \\
\text { public opinion, and public health }\end{array}$ & Michigan State University, USA \\
\hline Professor Bernd SCHMITT & $\begin{array}{l}\text { Creative strategy, branding and } \\
\text { customer experience management }\end{array}$ & Columbia Business School, USA \\
\hline Professor Stephan C. SCHUSTER & $\begin{array}{l}\text { Metagenomics, evolutionary biology } \\
\text { and ancient DNA }\end{array}$ & Pennsylvania State University, USA \\
\hline Professor Kerry SIEH & Earth Sciences & California Institute of Technology, USA \\
\hline Professor Stephen Kevin SMITH & Reproductive medicine and cancer & Imperial College London, UK \\
\hline Professor Paul TAPPONNIER & Earth Sciences & $\begin{array}{l}\text { Institut de Physique du Globe, } \\
\text { Paris, France }\end{array}$ \\
\hline Professor Nikolay ZHELUDEV & $\begin{array}{l}\text { Nanophotonics, metamaterials; } \\
\text { nonlinear optics, nanotechnology }\end{array}$ & University of Southampton, UK \\
\hline
\end{tabular}

NTU has succeeded in securing the lion's share, on a competitive basis, of the Singapore NRF Research Fellows. The NRF Research Fellows Scheme is a globally competitive programme to attract, recruit and root young scientists and researchers to conduct independent research in Singapore (Singapore NRF Fellowship programme: www.nrf.gov.sg/about-nrf/ programmes/nrf-fellowship. The Scheme is a key initiative to develop and nurture R\&D talent and build R\&D capacity in Singapore, and is open to all areas of science and technology. To date, since the programme started in 2007, NTU has attracted 24 out of 47 NRF Fellows to its schools. This is indicative of the high profile of NTU globally as a leading academic research hub firmly in the sights of early-stage academics keen to have a quick start to their research. Running parallel with the NRF Research Fellowship scheme is NTU's own Nanyang Assistant Professorship (NAP) scheme, which started in 2007. Nearly 2400 NAP applications were received in the 3 calls made in 2007 to 2012. NTU currently has 24 NAPs among the schools. Notably, the NRF Fellows and NAPs come from outstanding research universities and institutions worldwide.

Given the paramount importance of the faculty body as the intellectual engine and a critical success factor, NTU re-designed its appointment, promotion and tenure (APT) system in 2006. Designed to ensure high standards for the recruitment and retention of quality faculty talent, the new system injects greater objectivity and rigour into the promotion and tenure (PT) process. Key features include the employment of multi-level committee-based evaluation, a common evaluation system for the assessment areas of Research, Teaching and Service, built-in checks and balances, and use of mandatory external expert references. The first exercise in 2007 involved reviewing 603 existing faculty members, as it was conducted under the new tenure system.

The APT exercises have enabled NTU to conduct a thorough review of its intellectual capital, while the results have created the capacity for the infusion of fresh talent, both at the senior and junior level. As mentioned earlier, a number of world-renowned academics have been recruited to NTU since 2008, who in turn act as focal points to attract other eminent academics and researchers. A central budget has been set aside for such strategic hiring. Equally successful are our efforts to recruit outstanding and promising early-stage faculty.

The faculty salary structure has been revised following the reform of the APT system. The salary structure is now performance-based and aligned with market and international best practice. A 
weighted scoring system is used for performance appraisal, complemented by a ranking system based on a bell curve distribution to guard against appraisal inflation. As with the APT exercise, faculty are evaluated based on the metrics of research output, teaching and service to the university. Faculty must demonstrate strength in teaching, which includes advising, mentoring, curriculum development and innovation. In addition to student feedback score, the assessment of teaching contributions include pedagogical innovations, teaching awards, novel use of info-communication technology, teaching and learning, and the production or publication of teaching textbooks, materials, pedagogical software, etc. Relevant service contributions, both within and outside NTU, are considered for evaluation, and service excellence which has contributed to the academic group or beyond carries further weight. Examples of service contributions include (1) work which demonstrates strengths in management ability; (2) work which results in effective contribution to policy and academic governance activities; (3) significant roles in reviews and work at the national or international levels; and (4) significant contributions to the community and profession.

NTU has also focused strongly on the continued development of individual faculty. We have implemented new policies to assist newly recruited faculty in the early stage of their career. In line with international practice, all newly appointed faculty members receive a start-up grant on appointment, and, typically, at least $1 \mathrm{PhD}$ scholarship. The system allows them to concentrate on research with a reduced teaching load in the first $3 \mathrm{yr}$ of their appointment. Schools are encouraged to appoint senior advisors to mentor new faculty. We have also established 2 formal training courses in teaching and language skills for faculty.

\section{INNOVATION AND ENTERPRISE}

Innovation holds the key to boosting the economic competitiveness of Singapore, and NTU plays an important role in this effort as a key stakeholder in the education of the next generation of leaders. We have introduced new programmes such as an incubation scheme for aspiring student inventors, a support programme for $\mathrm{PhD}$ students interested in commercialising their research, and Technology Accelerators to serve as development arms for research areas with high potential for commercialisation. In recent years, NTU has also attracted techno- logically sophisticated multinational companies. With the recent increase in research activities, we expect a stronger flow-through to commercial outcomes in the years ahead.

NTU, in association with Singapore's Jurong Town Corporation, has developed an industrial and business park with a focus on green technology immediately adjacent to NTU. The CleanTech Park contains corporate research laboratories and light manufacturing facilities, and NTU has located translational facilities, innovation centres and incubators 1 there, effectively establishing the CleanTech Park as an extension of the NTU campus. The relocation of key research constituents to the CleanTech Park, in combination with NTU's intention to have a seamless connection with it, provides very good opportunities for industry-academia interactions, including spinoff companies and high-tech start-up companies.

Over the years, NTU's Nanyang Technopreneurship Centre has developed a unique experiential entrepreneurship programme with team building, real-life business tests with real investors, and global experience in the USA and China as hallmarks. We have an opportunity to further develop our entrepreneurship education with the establishment in NTU of the first Kauffman Campus outside the USA, a collaboration with the Ewing Marion Kauffman Foundation, preeminent in the world of entrepreneurship education.

NTU is also the joint third founding member of the World Entrepreneurship Forum (WEF) and hosted the 4th Annual Conference of the WEF in November 2011. This makes Singapore (NTU) the first founding member from Asia to join the forum and the first country in Asia to host the forum. NTU is due to host the 6th conference of the WEF at the end of 2013.

\section{CAMPUS PLANNING AND INFRASTRUCTURE}

A conducive physical environment is an important enabler of teaching, learning and research. Despite being located in land-scarce Singapore, NTU has a sprawling, beautiful and unique campus (http:// gallery.ntu.edu.sg/photos/main.php). Modern infrastructure and high-tech facilities sit alongside heritage buildings amongst large pockets of green, open spaces with natural waterways that are home to a rich biodiversity of flora and fauna. In line with our strategic thrust to play a major role in achieving a

1́ncubator means an entrepreneurial company set up by NTU faculty to commercialise a NTU-developed technology. 
sustainable earth, NTU adopts principles of sustainability in the physical development of the campus and many of our buildings have won internationally accredited Green Mark awards. Between 2005 and 2010, capacity was substantially boosted with the completion of new academic buildings (http:// gallery.ntu.edu.sg/photos/main.php) and upgrading of our social, sports and recreational facilities. The selection of NTU as the Youth Olympic Village of the inaugural Youth Olympic Games (YOG) that was held in Singapore in August 2010 also signified the confidence placed in NTU to provide a world-class environment for international athletes.

In 2008, NTU embarked on an ambitious process of planning for its future development. Through analysis of its assets and assessment of its potential, NTU, with its expertise in science and technology, aims to establish itself among the world's premier academic institutions. This Master Plan provides guidance for the university's planning and growth. Its recommendations envisage a measured expansion of facilities within NTU's Yunnan Garden Campus over the next $15 \mathrm{yr}$, with a planning legacy extending long beyond 2025. As well as addressing the needs of the campus' natural and constructed environment, the Master Plan is in accordance with the university's broader educational mission of encouraging a diversity of social and cultural experiences and fostering intellectual endeavour.

To strengthen the residential character of the university, various types of new residential accommodation, including undergraduate clusters, graduate and faculty residences, are being constructed (www. ntu.edu.sg/odfm/CampusMasterPlanImplementation/ Pages/default.aspx). Faculty housing will also be enhanced to achieve greater faculty-student interaction. Another aspect of campus planning relates to the development of new facilities and redevelopment of existing facilities that support the pedagogy embraced by the BRC. Key to this is the planned construction of 2 new Learning Hubs, which will house state-of-the-art facilities and provide $24 \mathrm{~h}$ daily access. Existing lecture theatres and tutorial rooms will be re-configured to support smaller class sizes and small-group teaching. To encourage self-directed learning, more pockets of space with fully equipped IT infrastructure will be created around campus, including in the library. The new Experimental Medicine Building and Clinical Sciences Building will also be constructed for the medical school.

Social interaction gives rise to creative ideas. Key to the campus plan is the creation of a new campus centre housing a broad mix of recreational, social and functional facilities and amenities at the heart of the campus, where students, faculty and staff can congregate, mingle and interact at all times of the day, 7 days a week. It will be the pulse of the university, drawing in alumni and visitors alike. Accessibility of the campus will also be improved through a public rail system to facilitate engagement with the wider community.

\section{CONCLUSION}

NTU sets its university policies independently of ranking metrics. Nonetheless, NTU's rise in university rankings has definitely provided visibility to the university. As a benchmarking and quality assurance driver, the university has also benefitted by ensuring that it obtains good scores in the various categories that are relevant to the progress of a university. When communicated and used correctly, rankings provide useful information.

The last 5 yr have been a period of rapid growth and development for NTU. It has been a period of deep re-structuring, major reforms, big initiatives and extensive renewal. Change was the norm. The result has been important progress in education and especially research. An opportunity exists for NTU to be among the top global universities and a world leader in specific fields. NTU is clearly on the ascent and we will build on the momentum to push further ahead, to realise the goals of NTU 2015. The great strides NTU has made in the quality of its faculty, staff and facilities, as well as the partnerships it has established with top institutions worldwide, are transformational in their impact and will propel NTU's future rankings.

Acknowledgements. The authors thank the 2 anonymous reviewers for their comments.

\section{LITERATURE CITED}

Anderson RD (2004) Germany and the Humboldtian model. European Universities from the Enlightenment of 1914. Oxford University Press

Badat S (2010) Global rankings of universities: a perverse and present burden. Whose interests are we serving? Global inequalities and higher education. Palgrave Macmillan GlobalTech Alliance. www.globaltechalliance.org/ (accessed 11 April 2013)

> Hazelkorn E (2007) The impact of league tables and ranking systems on higher education decision making. High Educ Manage Policy 19:1-24

Hazelkorn E (2008) Globalization, internationalization and rankings. Int High Educ 53:8-10 
IHEP (Institute for Higher Education Policy) (2009) Impact of college rankings on institutional decision making: Four country case studies. Institute for Higher Education Policy, Washington DC

Loobuyck P (2009) What kind of university rankings do we want? Ethical Perspect 16:207-224

Marginson S (2008) Globalization, national development and university rankings. International Symposium: University ranking: Global trends and comparative perspectives, 12-13 November 2008, Hanoi (electronic version available at www.cshe.unimelb.edu.au/people/ marginson_docs/VNU\%20rankings \%20symposium\%2013 \%20November\%202008.pdf)

New Straits Times (2013) Rankings: Giving Asian universities due recognition. 21 April. www.nst.com.my/ channels/learning-curve/rankings-giving-asian-univer sities-due-recognition-1.260336 (accessed 1 August 2013)

Editorial responsibility: Konstantinos Stergiou, Thessaloniki, Greece
Rauhvargers A (2011) Global university rankings and their impact. European University Association, Brussels. (electronic version available at www.eua.be)

Rauhvargers A (2013) Global university rankings and their impact - Report II. European University Association, Brussels. (electronic version available at www.eua.be)

Saisana M, D'Hombres B (2008) Higher education rankings: Robustness issues and critical assessment. How much confidence can we have in Higher Education Rankings? Office for Official Publications of the European Communities, Luxembourg

Science Watch (2010) The most-cited institutions in engineering, 1999-2009. http://archive.sciencewatch.com/ inter/ins/10/10febTOP20ENG/ (accessed 11 April 2013)

Teng A (2013) NUS, NTU rank high on list of top 100 Asia schools. The Straits Times, 11 April, pB5. http://news hub.nus.edu.sg/news/1304/PDF/100-st-11apr-pB5.pdf (accessed 1 August 2013)

Submitted: April 2, 2013; Accepted: September 4, 2013 Proofs received from author(s): January 15, 2014 